\title{
Do Employers Prefer Overqualified Graduates? A Field Experiment ${ }^{1}$
}

\author{
Dieter Verhaest ${ }^{2}$, Elene Bogaert ${ }^{3}$, Jeroen Dereymaeker ${ }^{4}$, Laura Mestdagh ${ }^{5}$, Stijn Baert ${ }^{6}$
}

Forthcoming in Industrial Relations

\begin{abstract}
We test whether employers prefer overqualified to adequately qualified job candidates. To this end, duos of fictitious applications by bachelor and master graduates are sent to real job openings with a bachelor's degree as a minimum requirement. For the overall sample, we find that overqualified master graduates are $19 \%$ more likely to be directly invited for a job interview and $11 \%$ more likely to get any positive reaction. This relative advantage for overqualified workers is found to be higher for bottleneck occupations. Relative preferences also differ across employers within labour market segments.
\end{abstract}

Keywords: Job Competition, Underemployment, Overqualification, Overeducation, Mismatch, Recruitment, Graduate Labour Market

JEL: I21, J24, M51

\footnotetext{
${ }^{1}$ We thank the editor and three anonymous referees for their constructive comments, which helped us to improve our manuscript. In addition, we are grateful to Nick Drydakis and participants of the Workshop of the European Network on Transitions in Youth (2015) and the European Association of Labour Economists (2016) for their useful suggestions on earlier versions of this paper.

${ }^{2}$ KU Leuven and Ghent University. Postal address: KU Leuven, Faculty of Economics and Business, Campus Brussels, Warmoesberg 26, B-1000 Brussels, Belgium; E-mail: Dieter.Verhaest@ kuleuven.be; Tel.: +32 2609 88 25; Corresponding author.

${ }^{3}$ Ghent University. Postal address: Ghent University, Faculty of Economics and Business Administration, Tweekerkenstraat 2, B-9000 Ghent, Belgium.

${ }^{4}$ KU Leuven; Postal address: KU Leuven, Faculty of Economics and Business, Campus Brussels, Warmoesberg 26, B-1000 Brussels, Belgium.

${ }^{5}$ KU Leuven; Postal address: KU Leuven, Faculty of Economics and Business, Campus Brussels, Warmoesberg 26, B-1000 Brussels, Belgium.

${ }^{6}$ Ghent University, University of Antwerp, Université catholique de Louvain and IZA. Postal address: Ghent University, Faculty of Economics and Business Administration, Tweekerkenstraat 2, B-9000 Ghent, Belgium; E-mail: Stijn.Baert@ugent.be.
} 


\section{Introduction}

It is well-established that many young workers are employed in jobs that require less education than is needed for their job - i.e. they are "underemployed" or "overqualified" (Hartog, 2000; McGuinness, 2006). One of the possible explanations for this finding is that, when job applicants are plentiful and wages are downwardly rigid, employers may rank these applicants on the basis of their qualification level (cf. Reder, 1955; Hall, 1974; Thurow, 1975; Okun, 1981). In such a context, investing in additional qualifications may not only allow one to apply for jobs with higher minimum requirements, it will also enhance one's chances to be selected for jobs for which these additional qualifications are not strictly required. The purpose of this paper is to put this hypothesis to a test. To this end, we conduct a field experiment in the Belgian graduate labour market. We send out fictitious applications of master and bachelor graduates to real vacancies for jobs requiring a bachelor degree. By monitoring the subsequent call-back from the employer side, the relative preference for the overqualified master or adequately qualified bachelor graduate is identified.

From a theoretical point of view, several reasons can be put forward why employers may rank overqualified master graduates first. First of all, having obtained a master degree may signal higher innate ability (Spence, 1973). Second, as Thurow (1975) assumed in his job competition model, an additional degree might serve as signal for higher trainability. Third, even if not fully utilised, the skills obtained during one's master's studies may not be fully useless and still generate a small but significant effect on productivity. Fourth, the unutilised skills of overqualified workers may be an asset in case of sudden changes in skill needs within the firm, for instance as a consequence of unforeseen economic situations (Mahy et al., 2015), technological breakdowns (Bulmahn and Kräkel, 2002) or simply because of unanticipated job absence and quits by existing employees.

For many reasons, though, employers may just as well be reluctant to call back and hire overqualified master applicants. Overqualified workers are often found to be less satisfied with their jobs than their co-workers (Korpi and Tåhlin, 2009; Verhaest and Omey, 2009), probably resulting in lower performance than potentially can be achieved. Moreover, a few studies also found them to engage more often in on-the-job search and quitting behaviour than their colleagues (Tsang et al., 1991; Robst, 1995; 
McGuinness and Wooden 2009), thus resulting in lost recruitment and training costs. Further, by being prepared to apply for bachelor level jobs and not managing to find a job requiring a master degree, these master applicants may just as well send negative signals towards employers (McCormick, 1990). Finally, it is generally found that overqualified workers earn a small but significant wage bonus in comparison to their adequately but lower qualified counterparts (Hartog, 2000; Rubb, 2003; Korpi and Tåhlin, 2009). Hence, even if overqualified master applicants are more productive, this has to be traded off against the eventual wage bonus that has to be paid to them.

Only a few studies, all relying on experimental methods, have already investigated the call-back and hiring decisions of employers regarding differentially qualified applicants in an empirical way. van Beek et al. (1997) conducted a stated preference experiment in which Dutch employers had to select job applicants with different attributes for lower-skilled jobs. While underqualified job seekers were found to be penalised in the selection process, the overqualified ones were not found to be treated differently from those being adequately qualified. More recently, Humburg and van der Velden (2015) performed a similar experiment in nine European countries. Recruiters were asked to select university graduates for a typical junior position. On average, those with a $\mathrm{PhD}$ were found to have lower chances to be recruited while bachelor and master graduates were treated equally. However, these results hided substantial heterogeneity, with recruiters in the UK having a preference for bachelor graduates and recruiters in several other countries, such as France and Germany, having a preference for master graduates. Finally, almost simultaneously to our experiment, two American studies each conducted a field experiment on the value of postsecondary qualifications in the American labour market. Considering several occupations, Darolia et al. (2015) did not find differences in call-back between job seekers with and those without an associate's degree. Similarly, Deming et al. (2016) did not find evidence that having any post-secondary business qualification increases one's chances of receiving a positive call-back for business jobs that do not require a bachelor degree.

In this paper, we provide further experimental evidence regarding employer preferences for differentially qualified applicants. Along with Darolia et al. (2015) and Deming et al. (2016), we are the first in the literature on this issue to leave the lab for the field. Even if stated choice experiments are well-spread in social sciences, there is substantial discussion in the literature about the extent to which 
hypothetical choices reflect real choices. At least, research indicates that even small differences in stated choice designs may generate substantial differences in performance of the experiment (e.g., Neill et al., 1994; Hainmueller et al., 2015). By conducting a field experiment, we overcome this problem, i.e. we investigate real behaviour with respect to the selection of job candidates. A major difference with the field experiments by Darolia et al. (2015) and Deming et al. (2016) is the focus of our study. While the aforementioned studies primarily dealt with the difference in labour market value between for-profit and public college degrees, we more explicitly focus on the comparison between overqualified and adequately qualified workers.

Our study differs in two more ways from the aforementioned experimental studies. First of all, we look at whether selection behaviour is heterogeneous depending on the content of the job and the type of firm and organisation. The productivity of overqualified workers and, as a consequence, also the callback decisions of employers are likely to differ across these dimensions. Mahy et al. (2015) for instance claim that overqualified workers are relatively more productive in high-tech jobs since their higher education may reduce the loss in productivity resulting from the introduction of new technologies. van der Meer and Wielers (1996) then again claim overqualified workers to be preferred when output is hard to measure, such as in the professional service sector. In this case, the employees' qualifications might serve as a legitimation to the clients of the quality of the offered service. Apart from differences across types of activities, also differences between public and private organisations may be expected. Public organisations often have to adhere to strict job invitation and recruitment rules, which may limit their ability to favour overqualified workers. Private firms, on the other hand, are more flexible to adapt their technologies to changes in labour supply and also have more opportunities to offer overqualified workers wage premiums and promotion opportunities (Dolton and Vignoles, 2000). We identify these potentially heterogeneous treatment effects across jobs and sectors by sending out our applications to vacancies for a strategically chosen set of different occupations.

Secondly, we also investigate to what extent the call-back decision regarding overqualified and adequately qualified applicants depends on the specific labour market context. We hypothesise that the overqualified master applicants are more likely to be treated favourably when vacancies are easier to fill. When labour market tightness is low, recruiters can be more selective (cf. Reder, 1955; Blanchard 
and Diamond, 1994; Baert et al., 2015). Further, the risk of reduced productivity and early job quitting by the master applicants may be assessed to be lower when they have less outside options. Moreover, this lack of outside options reduces the bargaining power of these overqualified workers and may thus also reduce the wage bonus that has to be paid to them. The opposite may be true when vacancies are difficult to fill and job opportunities are abundant, with employers even being suspicious about master graduates nevertheless being prepared to apply for jobs only requiring a bachelor degree. Consistent with this hypothesis, several studies already found that occupational downgrading and the likelihood to be overqualified is countercyclical (Teulings and Koopmanschap, 1989; Devereux, 2002, 2004; Pollman-Schult, 2005; Büttner et al., 2010). Rather than considering the overall business cycle, we investigate this issue by looking at variations in tightness across labour market segments.

\section{Experiment}

\subsection{Correspondence Testing}

For our analysis, we rely on correspondence testing as originally implemented to test for racial discrimination (Jowell and Prescot-Clarke, 1970; Riach and Rich, 1991; Bertrand and Mullainathan, 2004). Within this experimental framework, pairs of fictitious job applications, differing only by the attribute that is tested, are sent to real vacant jobs. By registering the subsequent call-back, unequal treatment based on this attribute can be identified. Since all the recruiter's decision making information is under control of the researcher, selection on unobservables is not an issue (Riach and Rich, 2002; Pager, 2007). More recently, correspondence experiments were also used to study the impact of previous labour market trajectory characteristics such as spells of unemployment (Kroft et al., 2013; Eriksson and Rooth, 2014), experience as an overqualified or underemployed worker (Baert and Verhaest, 2014) or student job experience (Baert et al., 2016). However, apart from Darolia et al. (2015) and Deming et al. (2016), only a few other recent studies already used this framework to test for the labour market value of education related outcomes. As in our study, Drydakis (2016) and Nunley et al. (2016) sent applications to bachelor level jobs. However, focussing on college major, the role of internships and university reputation, they did not include (overqualified) master applicants in their design. 


\subsection{Experimental Identities}

In line with the general correspondence testing framework, we sent duos of fictitious applications to real vacancies for starter jobs in Flanders, the Northern part of Belgium. One application was for a male graduate having obtained a few months earlier a bachelor degree (named the "bachelor applicant" hereafter) and another one for a male graduate having obtained a master degree at the same moment (named the "master applicant" hereafter). Both had completed their final degree in June 2014 and had become unemployed afterwards.

In Flanders, two different types of bachelor degrees can be obtained: a so-called professional bachelor degree, awarded by colleges ("hogescholen" in Dutch) and a so-called academic bachelor degree awarded by traditional universities. While the professional bachelor program is intended to prepare directly for the labour market, the academic bachelor program rather prepares for entrance into a master program. Master degrees are obtained by following one or more years of academic education and are only awarded by universities. Notwithstanding the fact that most of the master students enter their (master) program after having obtained an academic bachelor degree, a substantial number of students with a professional bachelor degree also proceed in a (related) master program. To be eligible for a master program, these students first have to follow a one-year so-called "bridging" program.

Given that an academic bachelor program intends to prepare for a master program rather than for the labour market, only a small minority enters the labour market immediately after having obtained such an academic bachelor degree. ${ }^{1}$ Hence, we assumed the bachelor applicant in our study to have obtained his degree in college. Further, to maximise the comparability of the applications, the master applicant in our study was assumed to have obtained the same bachelor degree at the same college two years earlier, after which he proceeded with a bridging and (one-year) master program. ${ }^{2}$

To further warrant comparability, two additional conditions were put forward regarding the college and university at which the applicants obtained their degree(s). First of all, we assumed both the bachelor and master degree to be obtained at a college and university that is part of the same so-called "university association". In Flanders, each college is obliged to be associated with one university. Such an association involves collaboration both in terms of education and research. Moreover, the university 
with which a college is associated is usually mentioned in all the college's official communication (e.g., in the college's logo), resulting in a high visibility to the broader public. Hence, there is unlikely to be a reputation mismatch between the colleges and the university that are part of the same association. Second, only colleges were selected that are located in the same urban agglomeration as the one of the university and the home residence of the fictitious applicant. Hence, the applications could not signal any difference in the applicants' attitude towards geographical mobility.

Given the aforementioned prerequisites, all applicants were assumed to have obtained their degree(s) at Ghent University or colleges associated with Ghent University and only at campuses located in the Ghent urban agglomeration. In terms of the number of students in higher education, Ghent is ranked first among all Flemish cities (the city of Brussels excluded) $)^{3}$ and the Ghent University association is ranked second among all associations (five in total). In terms of population, Ghent is the second biggest city of Flanders (the city of Brussels excluded). Moreover, although Ghent is located at the Western side of the geographical centre of the region, the largest part of the Flemish territory (including Antwerp and Bruges, respectively the biggest and third biggest city of Flanders) as well as Brussels-Capital Region ${ }^{4}$ can be reached within a reasonable travel time of one hour by car or public transport. This allows to apply for a majority of the vacant jobs being available for bachelor graduates in Flanders and BrusselsCapital Region.

For the fictitious applications sent, we selected bachelor programs conditional on the following four prerequisites: (A) such a program is being offered by one of the colleges associated with Ghent University and located in the Ghent agglomeration, (B) Ghent University offers a one-year master program that clearly fits in terms of field of study with this bachelor program, (C) Ghent University offers a one-year bridging program allowing to enter the master program after having obtained this bachelor program, and (D) more than a few students participate in the concerned bridging program. Condition (B) was added to ensure that eventual observed differences in call-back are only due to overqualification and not to differences in match with the vacant job in terms of field of study. For similar reasons, we also avoided relying on master degrees that are more specialised than the corresponding bachelor degree. Conditions (D) was added to ensure that employers perceive the bridging program not to be an uncommon way to obtain a particular master degree. These four conditions 
delivered a selection of bachelor and related master programs in the following five different domains:

(1) Business and Communication Science, (2) Industrial Science and Engineering, (3) (Applied) Computer Science and Engineering, (4) Health Care and (5) Social Work and Pedagogy. ${ }^{5}$ This broad range of domains guarantees that our outcomes are not specific for one particular field or occupational group. Moreover, it allows to differentiate between different sectors and organisations and between segments of the labour market that differ in the extent to which vacancies are easy or difficult to fill.

We assume that both applicants obtained their final degree during the same academic year (academic year 2013-2014) and did not experience any delay during their educational career. As a consequence, the master applicant is two years older (23 years) than the bachelor graduate (21 years) in our experiment. Alternative options, aimed to have applicants of the same age, would have been to add years of delay in education or additional years of unemployment in the resume of the bachelor applicant. However, two years of unemployment or delay in education may generate strong negative signals towards employers. Hence, this would largely complicate the interpretation of the results of our experiment. While also age may matter as a selection criterion, the impact of an age of 21 instead of 23 is likely to be much smaller. Moreover, being older at labour market entry can be considered to be an inherent implication of the decision to obtain an additional master degree. Hence, when assessing the labour market effects of this decision, this age effect should be taken into account as well. We will turn back to this issue in the discussion section.

\subsection{Resume Templates}

For each of the combinations of bachelor and master programs that were selected, we constructed two different types of resumes and motivation letters (type A versus type B) matching the general requirements of starter jobs for individuals graduated from such a program. At the level of the program, all resumes and motivation letters were identical concerning all crucial characteristics. However, to avoid detection, type A resumes and cover letters differed from type B ones concerning lay-out and inessential particularities. All applicants were single males born and living in the Ghent urban agglomeration and had graduated from a high school with a standard reputation. Further, we added the following characteristics to the resumes: a common Flemish sounding name, an address with an existing street 
name but a non-existing house number in a middle-class neighbourhood, a mobile phone number, an email address from a commercial provider, a birth date, the Belgian nationality, comparable language and computer skills, ${ }^{6}$ a driving licence, one or two sports activities, one or two practised socio-cultural activities and experience in two different student jobs without much relevance for the bachelor level jobs (e.g., student work as a shop assistant). Finally, each type of resume also mentioned a few similar subjectively assessed personal qualities (e.g., the applicant claimed that he was a flexible and communicative person). The motivation letters mentioned the job title for which one was applying, expressed one's interest in the job and highlighted (in a different wording) a number of aspects also mentioned in the resume.

For both types of resumes and cover letters, two versions were created only differing in whether it concerned a bachelor applicant or a master applicant. In total, we thus created four different resumes and cover letters for each program (type A-bachelor, type A-master, type B-bachelor and type B-master). In the motivation letter, two sentences were added revealing one's final degree and its main characteristics. ${ }^{7}$ In the resume, we added information on the full higher education career, consisting of the year(s) of participation, the name(s) of the college (and university), and the name(s) of the program(s). To avoid detection, slightly different wordings were used for resumes of type A and those of type B. The resumes and motivation letters are available upon request.

\subsection{Selected Job Openings}

Our experiment was conducted between November 2014 and April 2015. During this period, we selected and applied for vacancies from the online database of the Flemish Public Employment Agency. We confined ourselves to vacancies for starter jobs with a bachelor degree in one of the selected programs as minimum requirement to be hired. ${ }^{8}$ To avoid selecting master level jobs for which additional work experience could serve as a substitute for a master degree, we further restricted our experiment to vacancies for which work experience was not a necessary prerequisite. ${ }^{9}$ Further, we only applied for jobs in Flanders and Brussels-Capital Region located in districts within a reasonable distance from Ghent (maximum one hour travelling distance by car). Finally, we selected no more than one job from the same employer or organisation to avoid detection. In total, we were able to select 512 vacancies. 
Given that vacancies were selected with a bachelor degree as minimum requirement to be hired, the bachelor (master) applicant was defined to be adequately qualified (overqualified) for the job. While it is not unusual to measure overqualification relying on hiring requirements, these requirements may deviate from the minimum education required to perform the job (Dolton and Silles, 2003; Verhaest and Omey, 2006). This may be attributed to two different factors. One reason may be that employers adapt the hiring requirements specified in the vacancy in response to an oversupply or undersupply of job seekers. Another explanation may be that hiring requirements adapt with some delay to structural changes in the skills that are required. A recent study by Hershbein and Kahn (2015) suggests the latter explanation to be dominant. They found a substantial increase in hiring requirements during the great recession without any reversion afterwards. Hence, it seems that, during recessions, employers take the opportunity to restructure their workforce towards the skill needs resulting from technological changes. Given that our experiment was conducted in the aftermath of the great recession, this interpretation would imply that hiring requirements of the selected job postings largely aligned with education required for doing the job.

\subsection{Application Procedure and Call-Back Registration}

To each suitable vacancy, two applications were sent, one for a bachelor applicant and another one for a master applicant, thus resulting in a total of 1024 applications. To avoid detection, one type A application was always combined with one type B application. This results in two possible combinations (type A-bachelor combined with type B-master or type B-bachelor combined with type A-master). We balanced the use of these combinations within each educational domain. Hence, eventual differences in outcomes between bachelor and master applicants cannot be attributed to any differences in details between type A and type B resumes and motivation letters. The aforementioned combinations were sent to employers each time with one or two working days in between. To avoid any order effects, we alternated regarding the application (bachelor versus master and type A versus type B) that was sent first. We always applied relying on the resume and motivation letter mentioning the bachelor (and linked master) program that matched the one requested by the employer. ${ }^{10}$

We collected call-backs from the employers by means of email or mobile phone voicemail. The 
exact content of the responses was registered for each call-back and is available upon request. Right after collecting a positive reaction, we replied to the employers by means of an email in which the offer was declined. This should have minimised any inconvenience to the firm. Eventual responses received beyond 30 days after sending out the resume were always considered to be negative.

In our analysis, we apply two definitions of positive reactions: positive call-back in the strict sense and positive call-back in the broad sense. With a positive call-back in the strict sense, we mean that the applicant got an invitation for a face-to-face job interview. With positive call-back in the broad sense, we also include all other positive (interested) reactions such as the request to call back the employer or to provide more information about particular aspects of the resume or motivation letter.

\subsection{Variation in Characteristics of the Vacancies}

In our analysis, we subdivide the call-back registered depending on the characteristics of the tested vacancies. A first series of these vacancy characteristics that we consider are related to the content of the job and the type of the firm. First, we subdivide the sample on the basis of the educational domain (see Section 2.2) that is required for the job. Second, we look at differences across sectors of activity. To retrieve the sector of the firm, we relied on the information in the vacancy regarding the name and address of the recruiting firm. NACE sectoral $\operatorname{codes}^{11}$ of the main activities for each firm were obtained from the website of the ministry of economic affairs based on this name and address. For our analysis, we grouped these codes into the following five sectoral domains: (1) Manufacturing, Energy and Construction, (2) Wholesale, Retail, Catering, Transport and Communication, (3) Finance, Insurance and Intellectual Services, (4) Public Administration, Education, Culture and Membership Organisations, and (5) Health Care and Social Work Activities. ${ }^{12}$ Third, we differentiate between private and public organisations. Public organisations are defined as organisations either being directly controlled by a political authority or being predominantly publicly financed. ${ }^{13}$

Further, we will also look at heterogeneous treatment effects by the importance of the demand and supply conditions by differentiating between bottleneck vacancies and other vacancies. For this, we matched each vacancy with an occupation in the occupational classification of the Flemish Public Employment Agency. For each occupation, each year this agency assesses whether there are quantitative 
bottlenecks, qualitative bottlenecks or no bottlenecks. Quantitative bottleneck occupations are occupations with difficulties to fill vacancies because of pure quantitative shortages of applicants. ${ }^{14}$ Qualitative bottleneck occupations are occupations with difficulties to fill vacancies not just because a lack of applicants but because the "quality" (i.e. skills) of the applicants is not sufficient. This distinction is important since we expect call-back and hiring behaviour to depend on the source of the bottlenecks. As mentioned in the introduction, we expect the hiring chances of master graduates to be relatively less favourable in the case of quantitative bottlenecks. Regarding qualitative bottlenecks, however, we expect master graduates to have relatively more favourable invitation rates since their additional degree may compensate the problem of insufficient skills.

Finally, we split up the experimental data depending on a number of characteristics of the vacancy that reveal some more information about the specific aspirations of the employer in the context of the posted job. First, even if we only selected vacancies for which work experience was not a prerequisite to apply, it was sometimes mentioned that some work experience was nonetheless a plus point. We expect master degrees to have an advantage for these vacancies since a master degree may act as a substitute for lack of work experience. Second, part of the vacancies explicitly mentioned that the job was open to both bachelor and master graduates. Evidently, we expect the invitation rates for master (bachelor) graduates to be relatively more (less) favourable for these vacancies than for vacancies only mentioning a bachelor degree as requirement.

\subsection{Research Limitations}

We end this method section with a number of limitations related to our experimental design that were not already mentioned before. For an extended discussion about the ethical aspects of our method, we refer to Riach and Rich (2004).

A major limitation of our research design is its focus on a rather specific labour market outcome, i.e. the invitation for a first job interview. Since we confine ourselves to the first stage of the recruitment process, our analysis does not deliver direct information about differences in job finding rates. However, as Bertrand and Mullainathan (2004) argue, even in the case of small frictions in the job search process, one would expect differences in call-backs to be translated in differences in job offers. Moreover, given 
that job interviews are costly, easily observable characteristics such as educational degrees are likely to matter most in the first stage of the selection process (Eriksson and Rooth, 2014). Further, alternatives to overcome this problem, such as audit tests in which actors participate in job invitations, have been criticised for several (methodological) reasons (Heckman and Siegelman, 1993; Riach and Rich, 2002). For instance, actors may consciously or unconsciously adjust their behaviour according to their own beliefs regarding determinants of labour market success. Finally, field experiments on racial discrimination that nevertheless covered both stages of the recruitment process confirm that the first stage is decisive. Cédiey et al. (2008), for instance, found that differences in call-backs are responsible for $85 \%$ of the variation in job invitations by race.

Related to this first limitation, we only focus on the first job of graduates. As a consequence, our results cannot simply be translated to later stages in the career. It can be expected that differences in educational careers are less important for older workers than for younger ones, because differences in previous labour market careers may matter more for experienced job candidates. Nonetheless, bad labour starts are consistently found to have a persistent impact on future labour market outcomes (e.g., Gregg, 2001; Mroz and Savage, 2006). As such, focussing on first jobs is defendable. Moreover, this focus also has a main practical advantage when conducting correspondence experiments. When designing resumes for older workers, much more information has to be taken into account and a much larger diversity in profiles is possible. This complicates the development of resumes that are equivalent.

Finally, full representativity cannot be achieved. We only focus on male applicants with a degree within a strict set of domains and only apply for a particular set of jobs posted at the Flemish Public Employment Agency. This problem is inherent to the experimental framework and is traded-off against the benefit of resolving the endogeneity of educational choices with respect to labour market success. Nonetheless, as mentioned before, we tried to minimise the problem by focussing on a broad range of programs preparing for largely different occupations and sectors of employment. 


\section{Results}

The experimentally gathered data are analysed in two ways. In a first step (Section 3.1), we test whether the positive call back rates are significantly different between bachelors and masters. We do so both for the overall sample and for various subsamples differing in terms of characteristics of the tested vacancies. While this allows to assess whether the main conclusion is robust across segments, these analyses do not test for whether eventual differences in relative call-back across these vacancies are statistically significant and do not account for the fact that the considered vacancy characteristics may be correlated. Therefore, in a second step (Section 3.2), we also estimate a number of linear probability models with the individual application as observation unit and the call-back for this application as outcome variable (coded 1 in the case of a positive call-back and 0 otherwise). As explanatory variables, we include a degree dummy (coded 1 for a master application and 0 for a bachelor application) and interaction terms between this dummy and the vacancy characteristics. To account for unobserved heterogeneity at the vacancy level, we also include vacancy level fixed effects. ${ }^{15}$

\subsection{Call-Back Rates}

Table 1 reports the positive call-back rates for both types of graduates and relying on both definitions of call back. On the basis of the overall sample (Table 1, row 1), we find that master graduates get $20.5 \%$ immediate invitations for a job interview compared to only $17.2 \%$ invitations for bachelor graduates. The ratio of these call-back rates is 1.193 indicating that master candidates get $19.3 \%$ more invitations for a job interview (column (5)). This difference in job invitation rates is statistically significant at the $5 \%$ level. When defined in the broad sense, call-back rates are $38.3 \%$ and $34.4 \%$ for master and bachelor graduates respectively (Table 1, column (7) and (8)). Also this difference in call-back rates is statistically significant. On the basis of the overall sample, we can thus safely conclude that master graduates are treated more favourable than bachelors for jobs requiring a bachelor degree.

\section{$<$ Table 1 about here >}

Next, we split up the sample by a number of vacancy characteristics that are related to the content of the job and the type of organisation (row 2 to 4 ). Also in most of these subsamples, masters get more positive 
call-backs than bachelors. However, this difference is not always statistically significant and this significance sometimes differs between our two definitions of positive call-back. For instance, we do find significantly higher job invitation rates for masters than for bachelors when applying for jobs requiring a degree in Industrial Science and Engineering (row 2), for jobs in the sector of Finance, Insurance and Intellectual Services (row 3) or for jobs in the private sector (row 4). We indeed expected relatively favourable hiring chances for master graduates in these segments. However, in terms of any positive reactions, results are either statistically insignificant or, in the case of private sector vacancies, even point to an effect in the opposite direction.

Further, we look at the bottleneck status of the vacancy (row 5). In the case of quantitative bottleneck vacancies, master graduates are found to be $28.3 \%$ more likely to be invited for a job interview than bachelor graduates (Table 1, column 5). The overall positive call-back is $23.7 \%$ higher for master than for bachelor applicants (Table 1, column 9) for these vacancies. In both cases, the call-back rates are statistically different between bachelor and master graduates if evaluated at the $1 \%$ significance level. Alternatively, for occupations with qualitative or no bottlenecks, call-back ratios are close to 1 . These outcomes are contradictory to what was expected. In the next section, we will investigate whether this result also holds once other vacancy characteristics are taken into account.

Finally, we break down the data by whether the vacancy mentioned that some work experience was a plus point (row 6) and by whether it was explicitly stated that the job was open to both bachelor and master graduates (row 7). We expected a master degree to serve as substitute for lack of work experience, but this is not what we find. On the contrary, having a master degree seems to be an advantage only when applying for vacancies that do not mention experience as plus point. Further, for jobs not mentioning being open to master graduates, we do not find any difference in positive reaction rates. Hence, even if it is not mentioned that the job is also open to master graduates, they are still as likely to get a positive reaction as bachelor graduates. In the other case, when it is explicitly mentioned that the job is also open for masters, we do find that master graduates get more positive reactions than bachelors. For these jobs, they are $70.6 \%$ (38.2\%) more likely to get a job invitation (positive reaction) than bachelor graduates. However, the results also suggest that the invitation chances of bachelor applicants for these jobs $(17.5 \%)$ are at least as high as for other jobs (17.1\%). 


\subsection{Regression Analysis}

To investigate more profoundly whether the relative preference for master graduates depends on the vacancy characteristics by which we broke down our sample, we end with a regression analysis. Analyses are conducted both relying on the strict sense (Table 2) and the broad sense (Table 3 ) definition of positive call-back.

First, we estimate a regression including only a dummy for the type of degree (column 1). These results corroborate with those in the previous subsection: on average, master graduates are 3.3 percentage points more likely to be invited for a job interview (Table 2) and 3.9 percentage points more likely to get any positive reaction (Table 3). In a second model, we also include interaction terms between the type of degree and the required domain (column 2). These estimates suggest that the relative advantage for master degrees differs across educational domains. On the basis of both definitions of positive call-back, we find this relative advantage to be less strong for Business and Communication Science (i.e. the reference category) than for other domains.

Further, we look at whether the relative preference of master graduates depends on the type of firm and organisation (column 3 and 4). Therefore, we include interaction terms between the degree dummy and a number of sectoral dummies as well as with a dummy indicating the vacancy is for a job in a public organisation. Althoug our analyses in the previous subsection did not deliver significant call-back ratios for every sector and type of organisation, our regression analyses do not indicate that firm and organisation characteristics matter much. Only the interaction effect between the master degree dummy and the Finance, Insurance and Intellectual Services sector on the job invitation rate turns out to be statistically significant at the $10 \%$ level (Table 2 , column 4 ); the returns on a master degree are somewhat higher in this sector.

\section{<Table 2 and 3 about here>}

Next, we investigate whether recruitment behaviour depends on the bottleneck status of the occupation (column 5 and 6). In line with the findings in the previous subsection, our regression analysis indicates that the relative preference for master graduates is stronger for quantitative bottleneck vacancies than for other vacancies; the difference in the job invitation rate (overall positive call-back rate) between 
masters and bachelors is 6.5 (12.4) percentage points larger for quantitative bottleneck vacancies than for vacancies without any type of bottleneck (column 5). Interestingly, the observed differences in the relative preference for masters across required educational domain largely disappear once the bottleneck status of the vacancy is accounted for (column 6). Hence, most of the observed differences across educational domains seem to result from quantitative differences in labour market shortages. Only regarding the domain of Social Work and Pedagogy, we still do find the relative preference for master graduates to be stronger in comparison to the domain of Business and Communication Science.

Finally, we also include interaction terms between the degree dummy and dummies indicating that the vacancy mentioned work experience as a plus point or that the vacancy is open to both bachelor and master graduates (column 7). In line with our findings on the call-back rates, we do find the relative preference for master graduates to be much stronger when the vacancy explicitly mentions that the job is open to both bachelors and masters. This result holds for both definitions of positive call-back. Similarly, when relying on the broad positive call-back definition, we do find evidence on a stronger relative preference for master graduates in the case work experience is not mentioned as a plus point. These results remain intact if also the type of job and firm and the bottleneck status of the vacancy is accounted for (column 8).

\section{Discussion}

With this study, we aimed at investigating whether employers either prefer overqualified or adequately qualified applicants for vacant jobs. To this end, we conducted a randomised field experiment in the Belgian (Flemish) youth labour market in which we sent duos of fictitious applications (one for a bachelor graduate and one for a master graduate) to real job openings requiring a bachelor degree as minimum qualification. Along with reporting results for the overall sample, we looked at whether this preference for overqualified master graduates vis-à-vis adequately qualified bachelor graduates differs depending on the type of job and organisation and on whether vacancies are difficult to fill.

Our main results are as follows. First, relying on the overall sample, we found that the probability of receiving any positive reaction was about $11 \%$ higher for (overqualified) master applicants than for 
(adequately qualified) bachelor applicants. Moreover, masters were found to be about $19 \%$ more likely to be directly invited for a job interview. These differences in call-back proved to be statistically significant. Second, also at the level of most of the subsamples by vacancy characteristics, master graduates were found to have a higher call-back rate than bachelor graduates, but this difference was not always statistically significant. Alternatively, for none of the subsamples, we found statistically significant evidence for better job invitation chances for adequately qualified (bachelor) graduates. Third, additional regression analyses revealed that the relative preference for master graduates was particularly strong for occupations with quantitative bottlenecks, vacancies explicitly mentioning to be open to both bachelor and master graduates, vacancies not mentioning that some work experience may be a plus point and jobs requiring a degree in the domain of Social Work and Pedagogy.

These results have several important implications. First of all, they clearly reject that employers are reluctant to call back overqualified individuals. For many (but not all) jobs and segments, overqualified individuals are in front of the job queue as, for instance, Thurow (1975) assumed. These findings are consistent with the conclusions of other experiments, who indicated that, in most labour markets, employers are either indifferent between (moderately) overqualified and adequately qualified applicants or even prefer (moderately) overqualified graduates. It thus seems that arguments contra selecting overqualified applicants, such as lower job satisfaction and higher wage costs, are usually (more than) compensated by arguments in favour of selecting them, such as higher trainability or ability. The latter conclusion also aligns with Kampelmann and Rycx (2012) and Mahy et al. (2015) who showed that overqualification has a strong positive impact on firm productivity. Part of the explanation may be that overqualified labour market entrants are preferred since they are slightly older and thus, perhaps, more mature. But even if so, it does not reject our conclusion that graduates may enhance their place in the job queue for first jobs by postponing labour market entry through obtaining an additional degree.

A second implication is related to the heterogeneity in recruitment behaviour depending on the content of the job, sector of employment and the type of organisation. Once controlling for bottleneck vacancies, we did not find much evidence on systematic differences in recruitment behaviour with respect to adequately qualified and overqualified job candidates across these dimensions. In line with the claims of van der Meer and Wielers (1996), we found some indications that organisations within 
sectors with difficulties to measure product quality, such as the Finance, Insurance and Intellectual Services sector, are more likely to prefer overqualified job seekers. However, this finding was only barely statistically significant and did only show up relying on our positive call-back indicators. Further, we did not find evidence regarding the hypotheses that overqualified workers are relatively more preferred in typical high-tech occupations or in the private organisations. One explanation for this lack of evidence may be that eventual structural differences in recruitment behaviour across segments already translate in differences in the minimal requirements that are mentioned in the vacancies. However, given the small sizes of some of the subsamples, further research on this issue is advised. Conversely, our results suggest substantial differences in selection behaviour within sectors and across employers, with employers having a relative preference for master graduates explicitly mentioning that the vacancy is open to both bachelor and master graduates. This aligns with the conclusions of Humburg and van der Velden (2015), who also found substantial heterogeneity in recruitment behaviour among similar types of employers. It thus seems that there are significant differences in the opinions of recruiters about the extent to which a surplus of qualifications is beneficial to the firm, perhaps because recruiters have different past experiences in this respect.

Third, the abovementioned result regarding the difference between quantitative bottleneck and nonbottleneck vacancies refutes that overqualification is the result of employers being more selective when the relative supply of labour is high. This suggests that the often-observed countercyclicality of overqualification and overeducation rather results from an increase in job seekers' willingness to accept any type of jobs (cf. Dolado et al., 2009) or from changes in task assignments among existing workers (cf. Devereux, 2000) than from more selective recruitment policies. However, the question remains why employers facing quantitative bottlenecks are actually even more likely to invite overqualified master than adequately qualified bachelor graduates. One explanation for this finding may be that these jobs actually require a master degree for doing them but, to increase the pool of potential hires, these employers reduce the minimal qualification mentioned in the vacancy to the bachelor level. Additional employer-sponsored training may then help reducing the skill deficits in case a bachelor graduate has to be hired. However, for two main reasons, we do not expect this to be the dominant explanation. Firstly, since it would still be preferable to hire graduates with the appropriate education for doing the job, we 
would expect these employers to mention explicitly in the vacancy that the job is also open to master graduates. However, the correlation between quantitative bottleneck vacancies and vacancies mentioning the job is open to both bachelor and master graduates is close to zero in our sample. ${ }^{16}$ Secondly, we would expect employers to consider the selection of bachelor graduates for these jobs only as a last option, i.e. in the case little or no other applications are received. This is contradicted by our finding that the invitation rates of bachelor graduates for these jobs are still substantially higher than those for other jobs (see Table 1). Another explanation, as offered by an anonymous reviewer of a former version of our study, may be that these bottlenecks arise from jobs requiring higher ability and employers using a master degree as signal for this ability. However, also in this case, one would expect employers to mention explicitly in the vacancy that the job is open to master graduates. Moreover, this need for higher ability is likely to cause qualitative rather than quantitative bottlenecks. A last explanation for our finding of higher returns on a master degree in quantitative bottleneck occupations may be that these overqualified applicants are hoarded in view of eventual vacancies in the near future for related jobs with more responsibilities. As such, they anticipate to difficulties to fill these positions as well. But this is an interpretation that cannot be tested relying on our data and thus requires further investigation, for instance by tracking overqualified workers over time.

A fourth implication is related to the role of formal education as a substitute for other types of human capital. It is often argued that overqualification is the consequence of a lack of work experience and more practical skills (Sicherman and Galor, 1990). While our analysis focussed on vacancies for which experience was not a necessary prerequisite to be selected, it was often mentioned in the vacancy that some work experience was considered to be a plus. But conversely to expectations, we did not find overqualified master graduates to be preferred to adequately qualified bachelor graduates for these jobs. Similarly, we did not find selection chances to differ between both groups for vacancies with so-called qualitative bottlenecks, i.e. when vacancies are difficult to fill because of a lack of candidates with suitable skills. It thus seems that employers do not consider the additional skills obtained at university to be good substitutes for the other more practical skills that are required for these jobs. Of course, one may expect this conclusion to differ for overqualified workers with a vocational degree as surplus education. But to investigate this, additional research focussing on more intermediate levels of 
qualifications would be required.

One last implication is related to eventual crowding out effects. It is often claimed that overqualified job seekers crowd out adequately qualified job seekers so that these adequately qualified job seekers end up in jobs with lower functional levels or even in unemployment (Thurow, 1975). Although our study was not designed to test the crowding out hypothesis, our results provide some insights into the extent to which the selection behaviour of employers may contribute to such effects. On the one hand, to be able to crowd out adequately qualified workers, overqualified job seekers should be appealing to employers, as we found. On the other hand, we found the preference for overqualified workers to be particularly strong within vacancies for occupations with quantitative bottlenecks. One may expect that job queues are rather short for these jobs and, hence, that crowding out effects are, at best, rather moderate. At least, this interpretation is consistent with the conclusions of van Ours and Ridder (1995) and those of Gautier et al. (2002), who investigated the crowding out hypothesis directly and found only limited evidence for such effects.

\section{Conclusion}

To conclude, our analysis clearly indicates that being moderately overqualified for a vacant job should not be detrimental for being selected and, for some jobs, may even deliver an advantage. Of course, it should be stressed that our results only apply to the upper skill segments of the labour market. As the evidence on labour market polarisation shows (Goos et al., 2009), the context for the medium and lowskilled segments is largely different. Hence, further research is required to assess whether our results can be generalised to these segments as well. Moreover, other studies also suggest that returns to overqualification in terms of hiring chances differ across countries (e.g. Humburg and van der Velden, 2015; Deming et al. 2016). This may not only be caused by differences in labour market context, but also by international differences in the content and selectivity of bachelor and master programs. Given that these studies relied on stated choice experiments or that their focus was not explicitly on the comparison between overqualified and adequately qualified workers, we are in favour of future research complementing our results with findings for other countries. Further, we only focussed on rather 
moderately overqualified graduates. Research relying on stated choice experiments already suggested results to differ for more severely overqualified individuals (Humburg and van der Velden, 2015), but also regarding this issue additional research relying on experiments in the field is advised. Finally, given that our focus was purely on overqualification, we did not consider situations where the obtained bachelor or master degree was in a different field than the one required for the job. Similar research focussing on these alternative types of mismatches is another interesting avenue for further research.

\section{References}

Baert, Stijn, Bart Cockx, Niels Gheyle, and Cora Vandamme. 2015. 'Is There Less Discrimination in Occupations Where Recruitment Is Difficult?' ILR Review 68:467-500.

Baert, Stijn, Olivier Rotsaert, Dieter Verhaest, and Eddy Omey 2016. 'Student Employment and Later Labour Market Success: No Evidence for Higher Employment Chances.' Kyklos 69: 401-425.

Baert, Stijn, and Dieter Verhaest. 2014. 'Unemployment or Overeducation: Which is a Worse Signal to Employers?' IZA Discussion Papers No. 8312, Bonn: Institute for the Study of Labor.

Blanchard, Olivier, and Peter Diamond. 1994. 'Ranking, unemployment duration and wages', Review of Economic Studies 61: 417-434.

Bertrand, Marianne, and Sendhil Mullainathan. 2004. 'Are Emily and Greg more employable than Lakisha and Jamal? A field experiment on labor market discrimination.' American Economic Review 94: $991-1013$

Bozeman, Barry. 1987. All organizations are public: Bridging public and private organizational theories. San Francisco: Jossey-Bass.

Bulmahn, Guido, and Matthias Kräkel. 2002. 'Overeducated workers as an insurance device.' Labour 16: 383-402.

Büttner, Thomas, Peter Jacobebbinghaus, and Johannes Ludsteck. 2010. 'Occupational Upgrading and the Business Cycle in West Germany.' Economics: The Open-Access, Open-Assessment E-Journal 4, 2010-10.

Cédiey, Eric, Fabrice Foroni, and Hélène Garner. 2008. 'Discrimination à l'embauche fondée sur 
l'origine à l'encontre des jeunes français(e)s peu qualifié(e)s.' Dares Premières Infos Premières Synthèses 06.3.

Darolia, Rajeev, Cory Koedel, Paco Martorell, Katie Wilson, and Franciso Perez-Arce. 2015. 'Do employers prefer workers who attend for-profit colleges? Evidence from a field experiment.' Journal of Policy Analysis and Management 34: 881-903.

Deming, David, Noam Yuchtman, Amira Abulafi, Claudia Goldin, and Lawrence Katz. 2016. 'The value of postsecondary credentials in the labor market: an experimental study.' American Economic Review 106:778-806.

Devereux, Paul. 2000. 'Task assignment over the business cycle.' Journal of Labor Economics 18:98-124.

Devereux, Paul. 2002. 'Occupational upgrading and the business cycle.' Labour 16:423-452.

Devereux, Paul. 2004. 'Cyclical quality adjustment in the labor market.' Southern Economic Journal 70:600-615.

Dolado, Juan, Marcel Jansen, and Juan Jimeno. 2009. 'On-the-job search in a matching model with heterogeneous jobs and workers.' Economic Journal 119:200-228.

Dolton, Peter, and Mary Silles. 2003. 'The determinants and consequences of graduate overeducation.' In Overeducation in Europe, Current Issues in Theory and Policy, edited Felix Büchel, Andries de Grip, and Antje Mertens. Cheltenham: Edward Elgar.

Dolton, Peter, and Anna Vignoles. 2000. 'The incidence and effects of overeducation in the U.K. graduate labour market.' Economics of Education Review 19:179-298.

Drydakis, Nick. 2016. 'University Attended and Graduates' Labor Market Prospects: A Field Study for Britain.' Economics of Education Review 52: 192-208.

Eriksson, Stefan, and Dan-Olof Rooth. 2014. 'Do employers use unemployment as a sorting criterion when hiring? Evidence from a field experiment.' American Economic Review 104:1014-1039.

Gautier, Pieter, Gerard van den Berg, Jan van Ours, and Geert Ridder. 2002. 'Worker turnover at the firm level and crowding out of lower educated workers.' European Economic Review 46:523-538.

Goos, Maarten, Alan Manning, and Anna Salomons. 2009. 'The polarization of the European labor market.' American Economic Review 99:58-63. 
Gregg, Paul. 2001. 'The Impact of Youth Unemployment on Adult Unemployment in the NCDS.' Economic Journal 111:626-653.

Hainmueller, Jens, Dominik Hangartner, and Teppei Yamamoto. 2015. 'Validating vignette and conjoint survey experiments against real-world behavior.' Proceedings of the National Academy of Sciences 112:2395-2400.

Hall, Robert. 1974. 'The process of inflation in the labor market.' Brooking Papers on Economic Activity 2:343-393.

Hartog, Joop. 2000. 'Over-education and earnings: where are we, where should we go?' Economics of Education Review 19:131-147.

Heckman, James, and Peter Siegelman. 1993. The Urban Institute Audit Studies: Their Methods and Findings. Washington DC: Urban Institute.

Hershbein, Brad, and Lisa Kahn. 2015. 'Is College the New High School? Evidence from Vacancy Postings.' Paper presented at the Fourth World SOLE/EALE Conference, Montreal, 26-28 June 2015.

Humburg, Martin, and Rolf van der Velden. 2015. 'Skills and the graduate recruitment process: Evidence from two discrete choice experiments.' Economics of Education Review 49:24-41.

Jowell, Roger, and Patricia Prescott-Clarke. 1970. 'Racial discrimination and white-collar workers in Britain.’ Race \& Class 1970: 397-417.

Kampelmann, Stephan, and François Rycx. 2012. 'The impact of educational mismatch on firm productivity: Evidence from linked panel data.' Economics of Education Review 31:918-931.

Korpi, Tomas, and Michael Tåhlin. 2009. 'Educational mismatch, wages, and wage growth: Overeducation in Sweden, 1974-2000.’ Labour Economics 16:183-193.

Kroft, Kory, Fabian Lange, and Matthew Notowidigdo. 2013. 'Duration dependence and labor market conditions: evidence from a field experiment.' Quarterly Journal of Economics 128:1123-1167. Mahy, Benoit, François Rycx, and Guillaume Vermeylen. 2015. 'Educational mismatch and firm productivity: do skills, technology and uncertainty matter?' De Economist 163:233-262.

McCormick, Barry. 1990. ‘A Theory of Signalling During Job Search, Employment Efficiency, and "Stigmatised" Jobs.' Review of Economic Studies 57:299-313.

McGuinness, Seamus. 2006. 'Overeducation in the labour market.' Journal of Economic Surveys 
20:387-418.

McGuinness, Seamus, and Mark Wooden. 2009. 'Overskilling, job insecurity and career mobility.' Industrial Relations 48:265-286.

Ministerie van Onderwijs en Vorming 2015. Hoger Onderwijs in Cijfers - Aantal inschrijvingen op 31 Oktober 2014 Academiejaar 2014-2015. Brussels: Vlaamse Overheid.

Mroz, Thomas, and Timothy Savage. 2006. 'The Long-Term Effects of Youth Unemployment.' Journal of Human Resources 41:259-293.

Neill, Helen, Ronald Cummings, Philip Ganderton, Glenn Harrison, and Thomas McGuckin. 1994. 'Hypothetical surveys and real economic commitments.' Land Economics 70:145-154.

Nunley, John, Adam Pugh, Nicholas Romero, and R. Alan Seals. 2016. 'College Major, Internship Experience, and Employment Opportunities: Estimates from a Résumé Audit.' Labour Economics 38: $37-46$.

Okun, Arthur. 1981. Prices and Quantities: A Macroeconomic Analysis. Washington D.C.: Brookings Institution.

Pager, Devah. 2007. 'The use of field experiments for studies of employment discrimination: Contributions, critiques, and directions for the future.' Annals of the American Academy of Political and Social Science 609:104-133.

Pollman-Schult, Matthias. 2005. 'Crowding-out of Unskilled Workers in the Business Cycle: Evidence from West Germany.' European Sociological Review 21:467-480.

Reder, Melvin. 1955. 'The theory of occupational wage differentials.' American Economic Review $45: 833-852$.

Riach, Peter, and Judith Rich. 1991. 'Measuring discrimination by direct experimental methods: seeking gunsmoke.' Journal of Post-Keynesian Economics 14: 143-150.

Riach, Peter, and Judith Rich. 2002. 'Field Experiments of Discrimination in the Market Place.' Economic Journal 112:480-518.

Riach, Peter, and Judith Rich. 2004. 'Deceptive Field Experiments of Discrimination: Are They Ethical?’ Kyklos 57:457-470.

Robst, John. 1995. 'Career Mobility, Job Match and Overeducation.' Eastern Economic Journal 
21:539-550.

Rubb, Stephen. 2003. 'Overeducation in the labor market: a comment and re-analysis of a metaanalysis.' Economics of Education Review 22:621-629.

Sicherman, Nachum, and Oded Galor. 1990. 'A theory of career mobility.' Journal of Political Economy 98:169-192.

Spence, Michael. 1973. 'Job market signaling.' Quarterly Journal of Economics 87:355-374.

Teulings, Coen, and Marc Koopmanschap. 1989. 'An econometric model of crowding out of lower education levels.' European Economic Review 33:1653-1664.

Thurow, Lester. 1975. Generating Inequality. New York: Basic Books.

Tsang, Mun, Russell Rumberger, and Henry Levin. 1991. 'The Impact of Surplus Schooling on Worker Productivity.' Industrial Relations 30:209-228.

van Beek, Krijn, Carl Koopmans, and Bernard van Praag. 1997. 'Shopping at the labour market: A real tale of fiction.’ European Economic Review 41:295-317.

van der Meer, Peter, and Rudi Wielers. 1996. 'Educational credentials and trust in the labor market.' Kyklos 49:29-46.

van Ours, Jan, and Geert Ridder. 1995. 'Job matching and job competition: are lower educated workers at the back of the job queues?' European Economic Review 39:1717-1731.

VDAB 2015. Werkzoekende schoolverlaters in Vlaanderen, 28ste studie. Brussels: VDAB.

Verhaest, Dieter, and Eddy Omey. 2006. 'Measuring the incidence of over- and undereducation.' Quality \& Quantity 40:783-803.

Verhaest, Dieter, and Eddy Omey. 2009. 'Objective over-education and worker well-being: a shadow price approach.' Journal of Economic Psychology 30:469-481. 


\begin{tabular}{|c|c|c|c|c|c|c|c|c|c|}
\hline & $(1)$ & $(2)$ & (3) & $(4)$ & $(5)$ & $(6)$ & $(7)$ & $(8)$ & (9) \\
\hline & \multirow{2}{*}{$\begin{array}{c}\text { Number } \\
\text { of } \\
\text { selected } \\
\text { job } \\
\text { openings }\end{array}$} & \multicolumn{4}{|c|}{ Immediate Job Interview Invitation } & \multicolumn{4}{|c|}{ Any positive reaction } \\
\hline & & $\begin{array}{c}\text { Positive } \\
\text { call-back } \\
\text { rate } \\
\text { overall } \\
\end{array}$ & $\begin{array}{l}\text { Positive } \\
\text { call-back } \\
\text { rate } \\
\text { master }\end{array}$ & $\begin{array}{c}\text { Positive } \\
\text { call-back } \\
\text { rate } \\
\text { bachelor }\end{array}$ & $\begin{array}{c}\text { Call-back } \\
\text { ratio } \\
\text { master/ } \\
\text { bachelor }\end{array}$ & $\begin{array}{c}\text { Positive } \\
\text { call-back } \\
\text { rate } \\
\text { overall } \\
\end{array}$ & $\begin{array}{c}\text { Positive } \\
\text { call-back } \\
\text { rate } \\
\text { master }\end{array}$ & $\begin{array}{l}\text { Positive } \\
\text { call-back } \\
\text { rate } \\
\text { bachelor }\end{array}$ & $\begin{array}{c}\text { Call-back } \\
\text { ratio } \\
\text { master/ } \\
\text { bachelor }\end{array}$ \\
\hline 1. All vacancies & 512 & 0.188 & 0.205 & 0.172 & $1.193 * *$ & 0.363 & 0.383 & 0.344 & $1.114 * *$ \\
\hline \multicolumn{10}{|l|}{ 2. By required educational domain } \\
\hline Business and Communication Science & 152 & 0.102 & 0.092 & 0.112 & 0.824 & 0.306 & 0.289 & 0.322 & 0.898 \\
\hline Industrial Science and Engineering & 90 & 0.250 & 0.278 & 0.222 & $1.250 *$ & 0.456 & 0.489 & 0.422 & 1.158 \\
\hline Computer Science and Engineering & 58 & 0.284 & 0.328 & 0.241 & $1.357^{*}$ & 0.500 & 0.552 & 0.448 & $1.231 *$ \\
\hline Health Care & 120 & 0.292 & 0.317 & 0.267 & 1.188 & 0.446 & 0.483 & 0.408 & $1.184 * *$ \\
\hline Social Work and Pedagogy & 92 & 0.076 & 0.098 & 0.054 & 1.800 & 0.174 & 0.196 & 0.152 & $1.286 * *$ \\
\hline \multicolumn{10}{|l|}{ 3. By sector of activity } \\
\hline Manufacturing, Energy and Construction & 59 & 0.144 & 0.169 & 0.119 & $1.429 *$ & 0.305 & 0.322 & 0.288 & 1.118 \\
\hline Wholesale, Retail, Catering, Transport and Communication & 113 & 0.190 & 0.195 & 0.186 & 1.048 & 0.385 & 0.398 & 0.372 & 1.071 \\
\hline Finance, Insurance and Intellectual Services & 182 & 0.168 & 0.192 & 0.143 & $1.346^{* *}$ & 0.393 & 0.412 & 0.374 & 1.103 \\
\hline Public Administration, Education, Culture and Membership Org. & 56 & 0.134 & 0.143 & 0.125 & 1.143 & 0.330 & 0.339 & 0.321 & 1.056 \\
\hline Health Care and Social Work Activities & 149 & 0.232 & 0.255 & 0.208 & $1.226^{*}$ & 0.332 & 0.369 & 0.295 & $1.250 * *$ \\
\hline \multicolumn{10}{|l|}{ 4. By type of organisation } \\
\hline Private & 343 & 0.185 & 0.204 & 0.166 & $1.228 * *$ & 0.367 & 0.385 & 0.350 & 1.100 \\
\hline Public & 169 & 0.195 & 0.207 & 0.183 & 1.129 & 0.355 & 0.379 & 0.331 & $1.143 *$ \\
\hline \multicolumn{10}{|l|}{ 5. By bottleneck character of the vacancy } \\
\hline Quantitative bottleneck & 209 & 0.289 & 0.325 & 0.254 & $1.283 * * *$ & 0.498 & 0.550 & 0.445 & $1.237 * * *$ \\
\hline Qualitative bottleneck & 144 & 0.108 & 0.111 & 0.104 & 1.067 & 0.240 & 0.243 & 0.236 & 1.029 \\
\hline No bottleneck & 159 & 0.129 & 0.132 & 0.126 & 1.050 & 0.299 & 0.289 & 0.308 & 0.939 \\
\hline \multicolumn{10}{|l|}{ 6. By whether vacancy mentions some work experience is plus point } \\
\hline Not mentioned & 293 & 0.195 & 0.215 & 0.174 & $1.235^{* *}$ & 0.401 & 0.433 & 0.369 & $1.176^{* * *}$ \\
\hline Mentioned & 219 & 0.180 & 0.192 & 0.169 & 1.135 & 0.313 & 0.315 & 0.311 & 1.015 \\
\hline \multicolumn{10}{|l|}{ 7. By whether vacancy mentions job is open to both bachelors and masters } \\
\hline Not mentioned & 415 & 0.177 & 0.183 & 0.171 & 1.070 & 0.351 & 0.359 & 0.342 & 1.049 \\
\hline Mentioned & 97 & 0.237 & 0.299 & 0.175 & $1.706 * * *$ & 0.418 & 0.485 & 0.351 & $1.382 * * *$ \\
\hline
\end{tabular}


Table 2. Immediate job interview invitation: Linear probability estimates

\begin{tabular}{|c|c|c|c|c|c|c|c|c|}
\hline & $(1)$ & $(2)$ & (3) & $(4)$ & $(5)$ & $(6)$ & $(7)$ & $(8)$ \\
\hline Master & $\begin{array}{c}0.033 * * \\
(0.014)\end{array}$ & $\begin{array}{l}-0.020 \\
(0.026)\end{array}$ & $\begin{array}{l}-0.002 \\
(0.033)\end{array}$ & $\begin{array}{c}-0.064 \\
(0.042)\end{array}$ & $\begin{array}{c}0.006 \\
(0.023)\end{array}$ & $\begin{array}{l}-0.067 \\
(0.046)\end{array}$ & $\begin{array}{c}0.021 \\
(0.021)\end{array}$ & $\begin{array}{l}-0.083 * \\
(0.048)\end{array}$ \\
\hline Master x Industrial Science and Engineering educational program & - & $\begin{array}{l}0.075^{*} \\
(0.042)\end{array}$ & - & $\begin{array}{l}0.072 * \\
(0.043)\end{array}$ & - & $\begin{array}{c}0.025 \\
(0.057)\end{array}$ & - & $\begin{array}{c}0.001 \\
(0.056)\end{array}$ \\
\hline Master x Computer Science and Engineering educational program & - & $\begin{array}{l}0.106^{*} \\
(0.057)\end{array}$ & - & $\begin{array}{c}0.118^{* *} \\
(0.057)\end{array}$ & - & $\begin{array}{c}0.065 \\
(0.077)\end{array}$ & - & $\begin{array}{c}0.036 \\
(0.077)\end{array}$ \\
\hline Master $\mathrm{x}$ Health Care educational program & - & $\begin{array}{l}0.070 * \\
(0.042)\end{array}$ & - & $\begin{array}{c}0.108 * * \\
(0.053)\end{array}$ & - & $\begin{array}{c}0.080 \\
(0.059)\end{array}$ & - & $\begin{array}{c}0.068 \\
(0.058)\end{array}$ \\
\hline Master x Social Work and Pedagogy educational program & - & $\begin{array}{l}0.063^{*} \\
(0.037)\end{array}$ & - & $\begin{array}{c}0.106^{* *} \\
(0.048)\end{array}$ & - & $\begin{array}{c}0.110^{* *} \\
(0.048)\end{array}$ & - & $\begin{array}{c}0.102 * * \\
(0.046)\end{array}$ \\
\hline Master x Manufacturing, Energy and Construction sector & - & - & $\begin{array}{c}0.045 \\
(0.041)\end{array}$ & $\begin{array}{c}0.049 \\
(0.043)\end{array}$ & - & $\begin{array}{c}0.046 \\
(0.043)\end{array}$ & - & $\begin{array}{c}0.047 \\
(0.042)\end{array}$ \\
\hline Master x Finance, Insurance and Intellectual Services sector & - & - & $\begin{array}{c}0.050 \\
(0.038)\end{array}$ & $\begin{array}{l}0.066^{*} \\
(0.040)\end{array}$ & - & $\begin{array}{c}0.067 \\
(0.041)\end{array}$ & - & $\begin{array}{l}0.073 * \\
(0.040)\end{array}$ \\
\hline Master x Health Care and Social Work activities sector & - & - & $\begin{array}{c}0.060 \\
(0.041)\end{array}$ & $\begin{array}{c}0.033 \\
(0.044)\end{array}$ & - & $\begin{array}{c}0.025 \\
(0.043)\end{array}$ & - & $\begin{array}{c}0.038 \\
(0.043)\end{array}$ \\
\hline Master x Public organisation & - & - & $\begin{array}{l}-0.015 \\
(0.037)\end{array}$ & $\begin{array}{l}-0.036 \\
(0.039)\end{array}$ & - & $\begin{array}{l}-0.042 \\
(0.040)\end{array}$ & - & $\begin{array}{l}-0.038 \\
(0.039)\end{array}$ \\
\hline Master x Quantitative bottleneck vacancy & - & - & - & & $\begin{array}{l}0.065^{*} \\
(0.034)\end{array}$ & $\begin{array}{c}0.061 \\
(0.049)\end{array}$ & - & $\begin{array}{c}0.071 \\
(0.049)\end{array}$ \\
\hline Master x Qualitative bottleneck vacancy & - & - & - & - & $\begin{array}{c}0.001 \\
(0.034)\end{array}$ & $\begin{array}{c}0.011 \\
(0.037)\end{array}$ & - & $\begin{array}{c}0.022 \\
(0.036)\end{array}$ \\
\hline Master $\mathrm{x}$ Vacancy mentions some work experience is plus point & - & - & - & - & - & - & $\begin{array}{l}-0.022 \\
(0.029)\end{array}$ & $\begin{array}{l}-0.020 \\
(0.029)\end{array}$ \\
\hline Master x Vacancy mentions job is open to both bachelors and masters & - & - & - & - & - & & $\begin{array}{c}0.113 * * * \\
(0.037)\end{array}$ & $\begin{array}{c}0.110 * * * \\
(0.036)\end{array}$ \\
\hline
\end{tabular}

standard errors are between parentheses. $*(* *)((* *))$ indicates significance at the $10 \%(5 \%)((1 \%))$ significance level. Number of observations $=1024$ 
Table 3. Any positive reaction: Linear probability estimates

\begin{tabular}{|c|c|c|c|c|c|c|c|c|}
\hline & $(1)$ & $(2)$ & (3) & (4) & $(5)$ & (6) & (7) & $(8)$ \\
\hline Master & $\begin{array}{c}0.039 * * \\
(0.017)\end{array}$ & $\begin{array}{l}-0.033 \\
(0.032)\end{array}$ & $\begin{array}{c}0.007 \\
(0.038)\end{array}$ & $\begin{array}{l}-0.061 \\
(0.050)\end{array}$ & $\begin{array}{c}-0.019 \\
(0.027)\end{array}$ & $\begin{array}{l}-0.075 \\
(0.055)\end{array}$ & $\begin{array}{l}0.044 * \\
(0.024)\end{array}$ & $\begin{array}{l}-0.079 \\
(0.057)\end{array}$ \\
\hline Master x Industrial Science and Engineering educational program & - & $\begin{array}{l}0.100^{*} \\
(0.052)\end{array}$ & - & $\begin{array}{l}0.103 * \\
(0.056)\end{array}$ & - & $\begin{array}{c}-0.006 \\
(0.071)\end{array}$ & - & $\begin{array}{l}-0.034 \\
(0.071)\end{array}$ \\
\hline Master x Computer Science and Engineering educational program & - & $\begin{array}{c}0.136 * * \\
(0.062)\end{array}$ & - & $\begin{array}{c}0.143 * * \\
(0.063)\end{array}$ & - & $\begin{array}{c}0.022 \\
(0.088)\end{array}$ & - & $\begin{array}{l}-0.011 \\
(0.088)\end{array}$ \\
\hline Master x Health Care educational program & - & $\begin{array}{c}0.108 * * \\
(0.049)\end{array}$ & - & $\begin{array}{l}0.106^{*} \\
(0.062)\end{array}$ & - & $\begin{array}{c}0.044 \\
(0.072)\end{array}$ & - & $\begin{array}{c}0.030 \\
(0.071)\end{array}$ \\
\hline Master x Social Work and Pedagogy educational program & - & $\begin{array}{c}0.076^{* *} \\
(0.038)\end{array}$ & - & $\begin{array}{l}0.087 * \\
(0.045)\end{array}$ & - & $\begin{array}{c}0.097 * * \\
(0.046)\end{array}$ & - & $\begin{array}{c}0.089 * * \\
(0.044)\end{array}$ \\
\hline Master x Manufacturing, Energy and Construction sector & - & - & $\begin{array}{c}0.022 \\
(0.041)\end{array}$ & $\begin{array}{c}0.014 \\
(0.047)\end{array}$ & - & $\begin{array}{c}0.009 \\
(0.048)\end{array}$ & - & $\begin{array}{c}0.011 \\
(0.047)\end{array}$ \\
\hline Master x Finance, Insurance and Intellectual Services sector & - & - & $\begin{array}{c}0.031 \\
(0.045)\end{array}$ & $\begin{array}{c}0.044 \\
(0.046)\end{array}$ & - & $\begin{array}{c}0.048 \\
(0.046)\end{array}$ & - & $\begin{array}{c}0.060 \\
(0.046)\end{array}$ \\
\hline Master x Health Care and Social Work activities sector & - & - & $\begin{array}{c}0.071 \\
(0.045)\end{array}$ & $\begin{array}{c}0.051 \\
(0.051)\end{array}$ & - & $\begin{array}{c}0.034 \\
(0.050)\end{array}$ & - & $\begin{array}{c}0.052 \\
(0.050)\end{array}$ \\
\hline Master x Public organisation & - & - & $\begin{array}{l}-0.006 \\
(0.041)\end{array}$ & $\begin{array}{l}-0.020 \\
(0.043)\end{array}$ & - & $\begin{array}{c}-0.034 \\
(0.044)\end{array}$ & - & $\begin{array}{l}-0.030 \\
(0.043)\end{array}$ \\
\hline Master x Quantitative bottleneck vacancy & - & - & - & - & $\begin{array}{c}0.124 * * * \\
(0.039)\end{array}$ & $\begin{array}{c}0.143 * * \\
(0.062)\end{array}$ & - & $\begin{array}{c}0.150 * * \\
(0.062)\end{array}$ \\
\hline Master x Qualitative bottleneck vacancy & - & - & - & - & $\begin{array}{c}0.026 \\
(0.040)\end{array}$ & $\begin{array}{c}0.033 \\
(0.041)\end{array}$ & - & $\begin{array}{c}0.046 \\
(0.041)\end{array}$ \\
\hline Master $\mathrm{x}$ Vacancy mentions some work experience is plus point & - & - & - & - & - & - & $\begin{array}{c}-0.065^{* *} \\
(0.033)\end{array}$ & $\begin{array}{c}-0.054^{*} \\
(0.033)\end{array}$ \\
\hline Master x Vacancy mentions job is open to both bachelors and masters & - & - & - & - & - & - & $\begin{array}{c}0.121 * * * \\
(0.046)\end{array}$ & $\begin{array}{c}0.125^{* * * *} \\
(0.046)\end{array}$ \\
\hline
\end{tabular}

The value of the dependent variable is one in case of any positive reaction (positive call-back in the broad sense) and zero otherwise. All models also include a constant term and vacancy fixed effects. Robust standard errors are between parentheses. $*(* *)((* * *))$ indicates significance at the $10 \%(5 \%)((1 \%))$ significance level. Number of observations $=1024$. 
Notes

${ }^{1}$ According to the Flemish Public Employment Service (VDAB, 2015), only 1,004 (3.1\%) of all graduates entering the labour market in 2013 had an academic bachelor degree as opposed to $16,823(51.4 \%)$ graduates with a professional bachelor degree and 14,864 (45.5\%) graduates with an academic master degree.

2 During the academic year 2013-2014, 7,187 students participated in a bridging program at a Flemish university; during the same year, 20,214 students were inscribed for the first time in an academic bachelor program (Ministerie van Onderwijs en Vorming, 2015).

${ }^{3}$ A number of Flemish higher education institutions are located in the bilingual Brussels area. While Brussels ranks first in terms of the number of students in Belgium as a whole, this is largely due to participation in programs offered at colleges and universities of the French-speaking community.

${ }^{4}$ Belgium is a federal state consisting of three regions (Brussels-Capital Region, Flanders and Wallonia).

${ }^{5}$ A complete list of all programs that are included in each domain is available upon request.

${ }^{6}$ For most of the programs, these include standard computer skills such as the ability to work with Microsoft Office software. For particular programs, such as programs in computer science or electronics, also more specialised computer skills were added for both application types.

${ }^{7}$ As an example, we provide the sentences for graduates from programs in accountancy and taxation (domain business and communication science). The bachelor version of the type A motivation letter mentioned: "As a recently graduated bachelor in business management, with a specialisation in accountancy and taxation, I find this job an attractive challenge. In my bachelor education at college, I acquired valuable and relevant knowledge that will be useful in a job as [job title as mentioned in vacancy]." The bachelor version of the type B letter mentioned: "In June, I obtained my diploma of bachelor in Business Management, option Accountancy-Taxation. This professional program allows me to put relevant knowledge into practice." For the master version of the type A letter: "As a recently graduated master in business administration, with a specialisation in accountancy and taxation, I find this job an attractive challenge. Both in my bachelor education at college and my master education at university, I acquired valuable and relevant knowledge that will be useful in a job as [job title as mentioned in vacancy]." Lastly, for the master version of the type B letter: "After first having participated in a professional bachelor program, I obtained in June my diploma of master in Business Administration, option Accountancy and Taxation. This combination allows me to connect practice with the most recent scientific knowledge." 
${ }^{8}$ Also vacancies that explicitly mentioned to be open to both bachelor and master degree graduates were selected since the bachelor degree is the minimum requirement to be selected (cf. infra).

${ }^{9}$ The search interface of the Public Employment Agency allowed to select vacancies for which work experience was not a prerequisite to apply for the job. Nonetheless, many of these vacancies indicated in the description that work experience would be considered to be a plus. These vacancies were selected unless it was explicitly mentioned that work experience was a necessary prerequisite.

${ }^{10}$ In the case more than one of the selected programs were mentioned or in the case no details were provided regarding the requested specialisation (e.g., if the vacancy specified that a "bachelor in nursing" was required without mentioning further details), we selected the one matching most closely the job title.

${ }^{11} \mathrm{NACE}$ is the commonly used acronym for the Statistical Classification of Economic Activities in the European Union.

${ }^{12}$ Since for some firms more than one main activity was mentioned, some of them are categorised in more than one sectoral domain. In case more than three main activities were mentioned, we selected only the three most important activities. Activities of minor importance to the firm were not taken into account. For this assessment, we also relied on external sources such as the webpage of the firm.

${ }^{13}$ Our motivation to categorise the latter as belonging to the public sector is that they are likely to be, to a large extent, "constrained by public authority” (cf. Bozeman, 1987).

${ }^{14}$ In line with this definition, we find overall call-back rates for quantitative bottleneck vacancies in our sample to be (more than) twice as large as for other vacancies in our sample (see Table 1).

${ }^{15}$ We prefer linear probability models to probit models since including fixed effects in a probit model causes an incidental parameters problem. Another advantage is that the results of the linear probability model are easier to interpret. Estimating random effects probit models yielded similar results, although the interaction effect between the degree dummy and quantitative bottlenecks was only statistically significant for the positive call-back in the broad sense. These results are available upon request.

${ }^{16}$ This correlation is equal to 0.065 and not statistically significant at the $10 \%$ level. 